\title{
Annual suspended sediment concentration frequency analysis in Sefidroud basin, Iran
}

\author{
Ataollah Kavian $^{1} \cdot$ Smaeel Dodangeh $^{1} \cdot$ Zahra Abdollahi $^{1}$
}

Received: 10 February 2016/ Accepted: 27 February 2016/Published online: 15 March 2016

(C) Springer International Publishing Switzerland 2016

\begin{abstract}
Estimation of suspended sediment concentration (SSC) is crucial for water quality management, locating potential sites for fish habitat and reservoir dam regulations. This study aims at representing frequency analysis of annual SSC by applying several cumulative distributions in Sefidroud basin. Three preliminary tests were used to assess whether the data set comply with the hypothesis of homogeneity, stationary and randomness of the investigated time series. Then, frequency analysis of annual SSC carried out by applying different cumulative distribution functions. Goodness-of-fit tests indicated that 2-parameter distributions fit to annual SSC time series. Among the others, LN2, EV1, Logistic, GPAR distributions were the best fit distributions according to the Goodness-of-fit tests. The greatest values of SSC calculated for Ghareguni and YengiKand stations with quantities of 111,711.81 and 32,308.23 gr/L for 2 and 833,095.26 and $158,412.37 \mathrm{gr} / \mathrm{L}$ for 10 years return period respectively which should be considered for integrated erosion control projects.
\end{abstract}

Keywords Cumulative distribution function - Sefidroud basin $\cdot$ Suspended sediment concentration $\cdot 2$-parameter distribution

Ataollah Kavian

a.kavian@sanru.ac.ir

1 College of Natural Resources, Sari Agricultural Sciences and Natural Resources University, Po. Box 737, Sari, Mazandaran, Iran

\section{Introduction}

Suspended sediment load is a major challenge for water quality and quantity, hydroelectric equipment, fish habitat, reservoir sedimentation, channel morphology and consequence impacts on river flooding. Many studies conducted on erosion-sedimentation process modeling, have special respect to the suspended sediment concentration (SSC) because of its main role in representation of watershed sedimentation. Suspended sediments can account for $70-99 \%$ of the quantity of sediment transported by streams (Knighton 1998). Knowing the spatial and temporal variation of annual suspended sediment concentration (SSC) is a crucial variable about which, dam managers have always concerned. Annual SSC variation is a key practice for planning and management of water resources and dam regulations such as the time of water storage into and water release from dam. Suspended sediment concentration is therefore an important abiotic variable used to quantify water quality and habitat availability for some species of fish and invertebrate (Tramblay et al. 2008). From the above discussion, SSC is an important abiotic variable to quantify water quality. So there is an essential need to estimate SSC magnitude occur within the rivers annually especially for the regions where reservoir dams are in use at the outlet. Many researchs have been focused on the development of empirical relationships between specific sediment discharge and catchment physic-climatic variables (Demmak 1984; Probst and Amiotte Suchet 1992; Meddi 1992; Terfous et al. 2001; Benkhaled and Remini 2003; Achite and Ouillon 2007; Yan et al. 2013; Montanher et al. 2014; Wang and Tian 2013; Aulenbach 2013). In recent years researchers tried to do frequency analysis on SSC time series in order to quantify and predict annual extreme events of SSC and to determine SSC quantiles. 
SSC frequency analysis is an essential task for risk analysis related to any hydraulic structures construction projects during its design life such as reservoir dams. In frequency analysis of SSC, we are looking for what is the probability of occurrence of a specific SSC or greater values? FA is a method that allows relating the frequency of occurrence of an extreme event to its magnitude through the use of probability distributions (e.g. Rao and Hamed 2001; Chebana and Ouarda 2011). This technique is increasingly used by hydrologists to predict floods (Jaiswal et al. 2002; Kumar et al. 2003; Lim and lye 2003; Neslihan 2009; Sarhadi et al. 2012; Farsadnia et al. 2014), rainfall (Eslamian and Feizi 2007; Yurekli et al. 2009; Modarres and Sarhadi 2011; Hailegeorgis et al. 2013), low flows (Pearson 1995; Kroll and Vogel 2002; Chen et al. 2006; Modarres 2008a, b; Dodangeh et al. 2014), wind speeds (Modarres $2008 \mathrm{a}, \mathrm{b}$ ) and recently for dust storms (Dodangeh et al. 2012). However few studies attempted to apply this technique to predict sediment quantiles. Tramblay et al. (2008) employed FA technique to predict annual extreme events of SSC. They tried to fit probability distributions to stations data recorded to estimate the return period for a specific concentration or the concentration for a given return period. They showed that 2-parameter distributions like exponential, lognormal, Weibull and Gamma performed well to fit SSC data time series. Benkhaled et al. (2014), performed frequency analysis on SSC data in upstream of Foum El Gherza dam in southeast Algeria. They showed that 2-parameter log normal distribution (LN2) fitted well the considered data. While this technique is increasingly being used for hydro-climatic variables such as rainfall and extreme stream flow time series (Floods and low flows), on one hand, this method has not been a popular method to model magnitude frequency analysis of sediment transported by the rivers. On the other hand, although Sefidroud basin occupied by the severely erodible formations and characterized by the short-time intensive rainfalls carrying a large amounts of sediments into the dam lake, as one sixth of the reservoir volume is considered reservoir dead storage and a remarkable amount of sediments continue to cause a decreasing volume rate of $4 \%$ annually, but there have been no studies on the sediment concentration in this region. (Othman et al. 2013).

Sefidroud dam is a buttress- type concrete gravity structure one, and its height is $106 \mathrm{~m}$ (White 2001). The crest length is $425 \mathrm{~m}$, and the reservoir capacity was 1800 MCM at the beginning of operation. Approximately 600 MCM of this capacity is allocated for dead storage. The drain facilities can drain around $6000 \mathrm{~m}^{3} / \mathrm{s}$ and the annual adjustable water volume is 1650 MCM. The under cultivation area is 188,000 ha, and the installed power is $87,500 \mathrm{~m}^{3} / \mathrm{s}$. The maximum and minimum discharge during a statistic period are 2300 and $0.5 \mathrm{~m}^{3} / \mathrm{s}$ respectively.
The average discharge is $119.20 \mathrm{~m}^{3} / \mathrm{s}$ and the normal storage is $1276 \mathrm{MCM}$, finally the crest storage is 1760 MCM (Othman et al. 2013).

The present work will contribute to fill such a knowledge gap in this region applying FA techniques to quantify probability occurrence of annual maximum SSC and vice versa i.e. to quantify potential extreme concentrations can occur with different return periods or probabilities at the location of gauging stations. The results are required for quantifying fish habitat availability in rivers. It also helps managers to determine priorities of sub-watersheds for rehabilitation by bio-mechanical activities. The contents of the paper are structured as fallows follows: "Materials and methods" deals with geographical location of the study area and methods are also discussed in this section. The results are described in "Results and discussions" and a brief conclusion is also presented in the last "Conclusions".

\section{Materials and methods}

\section{Study area and data set}

Present study was conducted in Sefidroud basin which located in the arid and semi-arid regions of northwest Iran. Sefidroud basin that drains an area of approximately 56,700 square kilometer is known as one of the most important basins which provide water for 9 provinces of this country (Fig. 1). The average annual rainfall in this region varies between $400 \mathrm{~mm}$ in the west and $500 \mathrm{~mm}$ in the east. Ghezel Ozan River known as one of the major rivers of this area with a length of around $800 \mathrm{~km}$ originates from the upward Kurdistan Mountains and impounds into the Sefidroud reservoir which is the primary water source for many provinces especially for Guilan province. Guilan province located at downstream of the Sefidroud dam, is the main rice-production center in Iran. It is worth nothing that a total of $2400 \mathrm{~km}^{2}$ cultivated rice farms heavily depend upon water supplies from the Sefidroud reservoir (Othman et al. 2013). Under the effects of climate change, the hydrological response of the region has noticeably been changed such as a remarkable shift from snow to rainfall and the subsequent increases in quick-flow runoff in winter and early spring. This condition, accompanied by the human interference through the land use change, deforestation and disposal of rangelands in the vast space, resulted in accelerated erosion and soil leaching throughout the region. Under this condition, the capacity of the lake of Sefidroud dam has strongly been reduced due to the reservoir siltation. Each year a total of 32 million ton sediment deposited within the lake of the dam and now the volume of the reservoir reached to the half of it at the time 


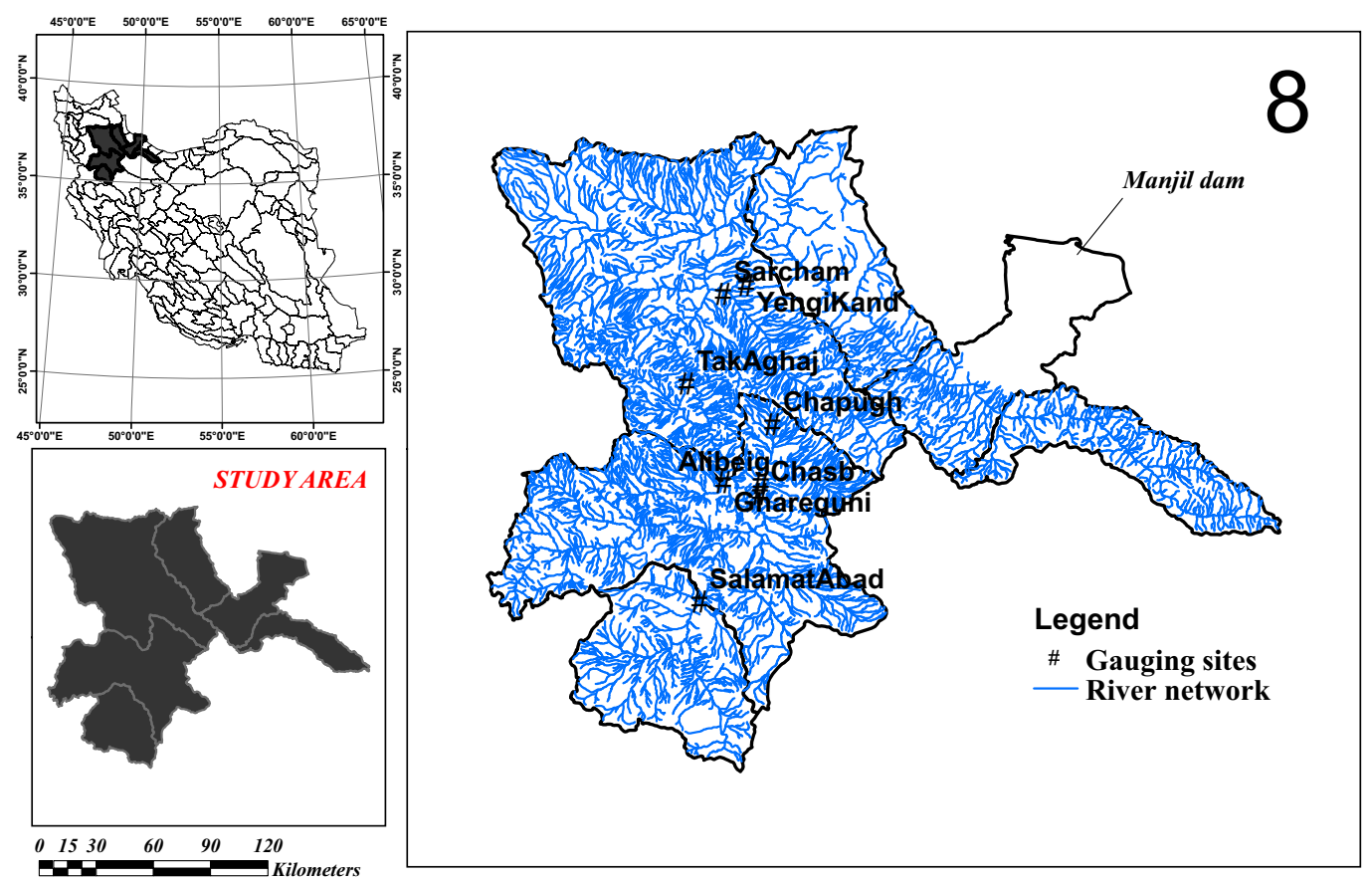

Fig. 1 Location map of the sediment gauging stations along the Ghezel Ozan River

Fig. 2 Pictures of sediroud Dam, have been filling with suspended sediment
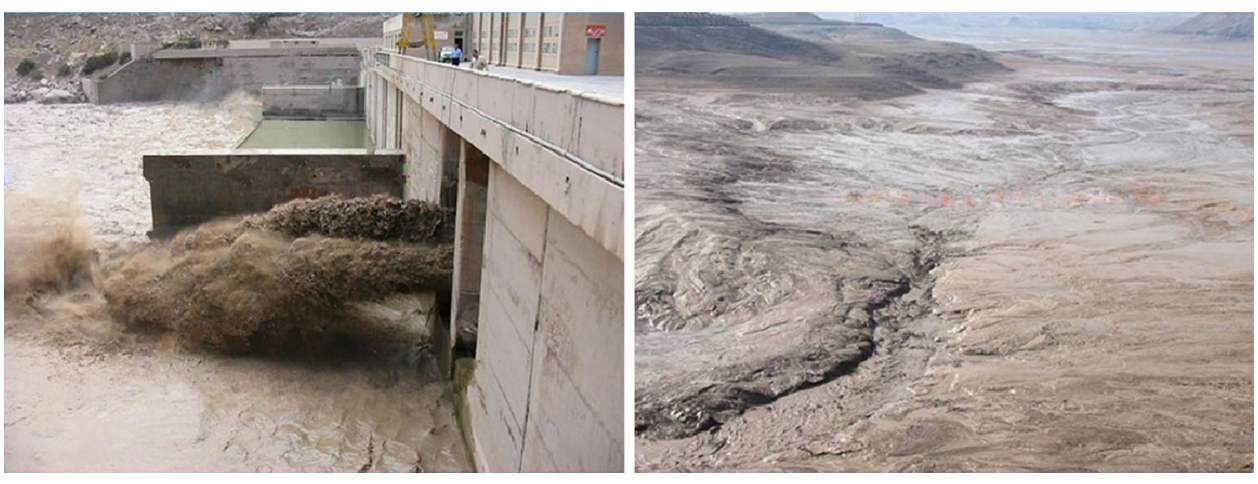

of construction (The volume of the lake of 1.8 Milliard cubic meters at the time of construction reached to the 900 million cubic meters now) (Fig. 2).

In this study, annual suspended sediment concentration (SSC) data of eight gauging stations located along the Ghezel Ozan River and its tributaries, were compiled from the Iran ministry of power. The location of these stations has been illustrated in Fig. 1. The data series of 12 stations, cover the time spans of different record lengths so that the shortest length of data belongs to Sohrein station (with the record length of 10 years) and the longest record belongs to Yengi Kand and Ghareguni stations (with the record length of 31 years). It is worth nothing that scare and short length data record of suspended sediment data is a common problem in the country, especially in arid and semi arid regions. The max annual suspended sediment concentrations and their related discharges of each selected station are presented in Table 1.

\section{Method}

Frequency analysis is a statistical approach commonly used in hydrology to relate the magnitude of extreme events to a probability of occurrence (Rao and Hamed 2001).

The main objective of frequency analysis is to infer the probability of exceedence of all possible events, in this case suspended sediment concentrations, from observed values (a sample of the parent population). The process of frequency analysis includes two main steps: (1) preliminary data processing in spite of checking randomness, stationary and homogeneity which are basic assumptions for frequency analysis, must data time series meet to them 
Table 1 The maximum annual suspended sediment concentrations and their related discharges of each selected station

\begin{tabular}{llcr}
\hline Station & Date & Max annual SSC $(\mathrm{gr} / \mathrm{L})$ & Related discharge $\left(\mathrm{m}^{3} / \mathrm{s}\right)$ \\
\hline Ghareguni & March 30, 1998 & $820,866.4$ & 23,060 \\
YengiKand & April 24, 2004 & $259,434.2$ & 73,500 \\
Alibeig & April 5, 2004 & 2773.248 & 8970 \\
TakAghaj & May 5, 2012 & $17,480.280$ & 7770 \\
SalamatAbad & March 19, 1998 & $131,700.1$ & 7820 \\
Sarcham & June 18, 2009 & $208,255.4$ & 74,310 \\
Chasb & May 4, 2002 & 637.212 & 12,970 \\
Chapugh & April 11, 2007 & 61.329 & 640 \\
\hline
\end{tabular}

and (2) carrying out the frequency analysis by fitting various probability distributions, selecting the best fitted one, parameter estimation of the best fit distribution and risk assessment based on quantiles or return periods. Using the fitted probability distribution, it is possible to predict the probability of exceedence for a specified magnitude (i.e. quantile) or the magnitude associated with a specific exceedence probability (Tramblay et al. 2008).

\section{Preliminary tests of stationary, randomness and homogeneity}

1. The Mann-Kendall test is used for determining the existence of statistically significant trends in climate and hydrologic time series (Burn 1994; Pasquini et al. 2006). This is a test for correlation between sequences of pairs of values. Using rank eliminates the sensitivity of the correlation test to the function linking the pairs of values. In particular, the standard correlation test is used to find linear relations between test pairs, but the rank correlation test is not restricted in this way.

2. Autocorrelation functions are commonly used for checking randomness in a data set. This randomness is ascertained by computing autocorrelations for data values at varying time lags. If random, such autocorrelations should be near zero for any and all time-lag separations. If non-random, then one or more autocorrelation values will be significantly non-zero. These functions were used to test the randomness of annual suspended sediment concentration time-series.

The randomness of the data set was tested by the autocorrelation function for the confidence bands (CB) given by:

$C B=\frac{Z_{i}=\alpha / 2}{\sqrt{n}}$

where $\mathrm{z}$ is the percent point function of the normal distribution, $\mathrm{n}$ is the sample size and $\mathrm{a}$ is the significance level. Thus, the CB have fixed width that depends on the sample size.
3. Thom's test (or run test) is usually used to assess homogeneity of time series by computing variations of the time series from a central value, usually median. Thom's test is described in detail by Rodrigo et al. (1999).

\section{Frequency analysis}

Frequency analysis is done by fitting appropriate probability distributions to the stationary, homogeneous and independent data time series to predict the probability of exceedence for a specified magnitude (quantile) or the magnitude associated with a specific exceedence probability (Benkhaled et al. 2014). After selecting a good distribution, parameters need to be estimated. Several methods, including the method of moments and maximum likelihood (ML) are extensively being used for this purpose. In recent years, probability weighted moments (PWMs) has been developed for parameter estimation of the distributions fitted to the hydrological time series. Probability weighted moments was defined by Greenwood et al. (1979) as follows:

$M_{P, r, s}=E\left[X^{p} F^{r}(1-F)^{s}\right]=\int_{0}^{1}[X(F)]^{p} F^{r}(1-F)^{s} d F$

The following two moments are usually considered:

$M_{1,0, s}=\alpha_{s}=\int_{0}^{1} x(F)(1-F)^{s} d F$

$M_{1, r, 0}=\beta_{r}=\int_{0}^{1} x(F) F^{r} d F$

$\alpha_{s}$ and $\beta_{r}$ are related as follow:

$\alpha_{s}=\sum_{k=0}^{s}\left(\begin{array}{l}s \\ k\end{array}\right)(-1)^{k} \beta_{k}$

$\beta_{r}=\sum_{k=0}^{r}\left(\begin{array}{l}r \\ k\end{array}\right)(-1)^{k} \alpha_{k}$ 
To select an appropriate distribution which best fit the data time series a number of statistical tools can be considered including graphics, goodness of-fit-tests and selection criteria. One of the graphical tools discriminate the best fitted distribution among the others is plotting-position.

Plotting position estimators of sample PWMs are driven by the following equations:

$a_{s}=\alpha_{s}=\frac{1}{n} \sum_{i=1}^{n}\left(1-p_{i: n}\right)^{s} x_{i}$

$b_{r}=\beta_{r}=\frac{1}{n} \sum_{i=1}^{n}\left(p_{i: n}\right)^{r} x_{i}$

where $\mathrm{P}_{\mathrm{i}: \mathrm{n}}=$ plotting position. Plotting position is a tool for visual inspection and can be used to compare sample frequency distribution with population frequency distribution.

Many literatures have demonstrated that graphical tools are not sufficient for selecting distributions (Ouarda et al. 1994; El Adlouni et al. 2008; Hebal and Remini 2011). Therefore non-graphical tools are also considered in this study. The Klomogorov-Smirnov and Chi square tests were used to verify the hypothesis concerning the parent distribution of the sample.

\section{Results and discussions}

\section{Test for randomness}

Autocorrelation functions were used to test randomness of the annual suspended sediment concentrations time series. Figure 3 shows ACFs for the annual suspended sediment concentrations time series of the selected stations across the study region. As the figure shows, all autocorrelation coefficients fall within the $95 \%$ confidence limits.
Therefore we can conclude that all of the investigated time series are strongly random. It may be attributable to the unregulated characteristics of the streams within the reach these measuring stations are located.

The run test's statistic for suspended sediment concentrations are also given in Table 2 . It is observed that all time series show homogeneity with having $P$ value $>0.05$ which confirm the results of ACFs in favor of unregulated flows at the gauging stations.

\section{Identification of best fit distributions}

At this section, the priority of the candidate distributions which best fit to the SSC data set was examined by applying the plotting position formula as well as by Klomogorov-Sminov and Chi-square statistic criterion. The candidate regional distributions are generalized logistic, extreme value, normal, Pareto and Pearson-III distributions. The efficiency of each probability distribution to fit the SSC data was evaluated based on the KlomogorovSmirnov and Chi square tests and results are summarized in Table 3. Results show that 2-parameter distributions identified as the best fitted distributions to the SSC time series. The only 3-parameter distribution in this study was GPAR distribution which fitted to the SSC data time series recorded at Alibeig station. The four distributions discriminated as the best fit distributions among the others are Logistic, EV1, GPAR and LN2 distributions, most of them are 2-parameter. Having well performance of GPAR distribution at the Alibeig station may be attributed to the local generation mechanisms resulted in complexity of SSC time series at this site. Tramblay et al. (2008) implied that 2-parametr distributions such as Log normal, Exponential, Weibul and Gamma distributions fit the annual maximum SSC better than 3-parameter distributions including the Generalized Pareto distribution so that time
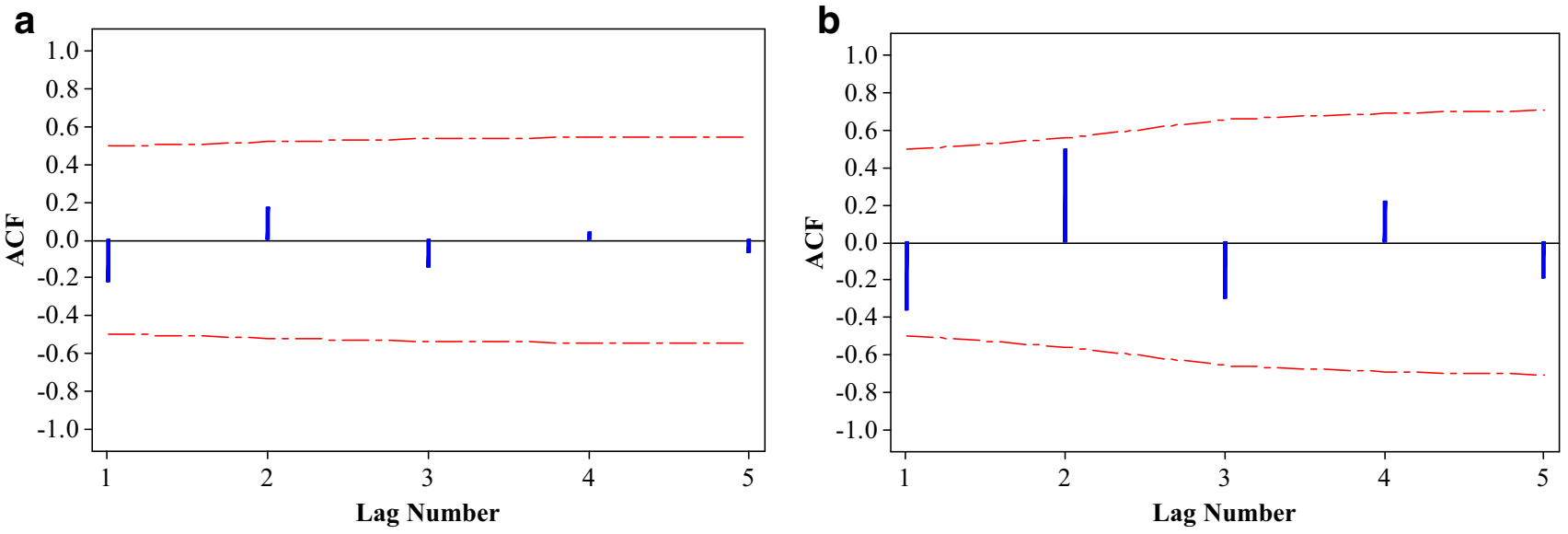

Fig. 3 Autocorrelation plots for the annual suspended sediment concentrations of the Ghareguni (a) and YengiKand (b) stations 
Table 2 Results of homogeneity and stationary tests of the selected stations

\begin{tabular}{lllllc}
\hline Station & \multicolumn{2}{l}{ Run test } & & \multicolumn{2}{l}{ Mann-Kendall } \\
\cline { 2 - 3 } \cline { 5 - 6 } & P value & Test statistic & & P value & Test statistic \\
\hline Ghareguni & 0.21 & 1.21 & & 0.20 & -0.23 \\
YengiKand & 0.21 & 1.21 & & 0.06 & 0.28 \\
Alibeig & 0.42 & -0.77 & & 0.62 & -0.1 \\
TakAghaj & 0.78 & 0.3 & & 0.63 & 0.12 \\
SalamatAbad & 1 & 0 & 0.91 & 0.05 \\
Sarcham & 0.21 & 1.21 & & 0.08 & -0.31 \\
Chasb & 0.33 & 1 & & 0.29 & -0.28 \\
Chapugh & 0.35 & 0.90 & & 0.88 & -0.05 \\
\hline
\end{tabular}

series of SSC of just 5 stations of total of 208 stations were fitted to GPAR distribution. Benkhaled et al. (2014) also suggested 2-parameter distributions to fit SSC rather than 3 -parameter distributions. They showed that 2-parameter log normal distribution has the best fit among the others.

\section{Frequency analysis and quantile estimation of SSC}

Quantile estimation of the investigated variable (SSC in this study) is one of the main tasks of the frequency analysis. The best fitted distributions presented in the previous section were then used to calculate magnitude of the SSC quantiles at different 2, 5, 10, 20, 30, 50, 100 and 200 years return periods (Fig. 4). Table 4 shows the result of quantile estimation for the selected stations and at different return periods. It is clear from the table that maximum return period of extreme SSC data observed in the region is 10 years return period. There is not observation data for return period greater than 10 years. It means that maximum amount of SSC in all gauging stations over the region, correspond to 10 years return period and occur in sequence of each 10 years. Increasing return period (from 2 to 200 years), the quantile values increases with lower occurrence probability in each year. Lowest values of SSC are seen at Chapugh station. The SSC value for this station varies between 0.4 and $50 \mathrm{gr} / \mathrm{L}$ for 2- and 10-year return period respectively. Similar values are also presented for Chasb station in Table 4. The lowest value of SSC for this station is equal to $24.64 \mathrm{gr} / \mathrm{L}$ with occurrence of 2-year return period and maximum value is $527 \mathrm{gr} / \mathrm{L}$ with occurrence of 10 years return period. Sarcham and SalamatAbad stations show similar values of approximately 2000 and $3000 \mathrm{gr} / \mathrm{L}$ for 2 years return period and 149,000 and $121,000 \mathrm{gr} / \mathrm{L}$ for 10 years retun periods respectively. TakAghaj and Alibeig have the same condition as well. But two stations with greatest values of SSC occurred in 2 and 10 years return periods are YengiKand and Ghareguni stations showing 32,308 and $111,711 \mathrm{gr} / \mathrm{L}$ for each 2 years return period and 158,412 and $833,095 \mathrm{gr} / \mathrm{L}$ for 10 years return periods respectively.

\section{Conclusions}

Estimation of suspended sediment concentrations (SSC) is an essential task for watershed science researchers and reservoir dam operators for optimum land use planning and management and determining the life time of the hydraulic structures. This study was conducted to provide probability occurrence of maximum SSC quantiles for different return periods in Sefidroud basin, Northwest Iran. The results showed that in comparison to the 3-parameter distributions, 2-parameter distributions have better performances to fit annual maximum SSC data time series except for Alibeig station. For the remaining stations, 2-parameter distributions preferred to 3-parameter distributions. Among the 2-parameter distributions, Logistic, EV1 and LN2 distributions showed better performances. Logistic distribution showed the best fit to the SSC data time series of Ghareguni, Sarcham and Chapugh gauging stations. EV1 was selected as the best fitting distribution at the YengiKand and Chasb stations. For Takaghaj and SalamatAbad stations, 2-parameter LN2 distribution performed better than
Table 3 Goodness-of-fit test using Klomogorove-Smirnov and Chi square tests and best fitted distribution

\begin{tabular}{|c|c|c|c|c|c|}
\hline \multirow[t]{2}{*}{ Station } & \multirow[t]{2}{*}{ Distribution } & \multicolumn{2}{|l|}{ Chi square } & \multicolumn{2}{|c|}{ Klomogorov-Smirnov } \\
\hline & & Statistic value & $\mathrm{p}$ value & Statistic value & $\mathrm{p}$ value \\
\hline Ghareguni & Logistic & 14.89 & 0.03 & 0.2 & 0.2 \\
\hline YengiKand & EV1 & 22 & 0.003 & 0.23 & 0.24 \\
\hline Alibeig & GPAR & 5 & 0.66 & 0.16 & 0.76 \\
\hline Takaghaj & LN2 & 4 & 0.78 & 0.2 & 0.67 \\
\hline SalamatAbad & LN2 & 4.40 & 0.73 & 0.17 & 0.87 \\
\hline Sarcham & Logistic & 54 & 0 & 0.34 & 0.02 \\
\hline Chasb & EV1 & 11.55 & 0.117 & 0.35 & 0.107 \\
\hline Chapugh & Logistic & 25.77 & 0.001 & 0.35 & 0.05 \\
\hline
\end{tabular}



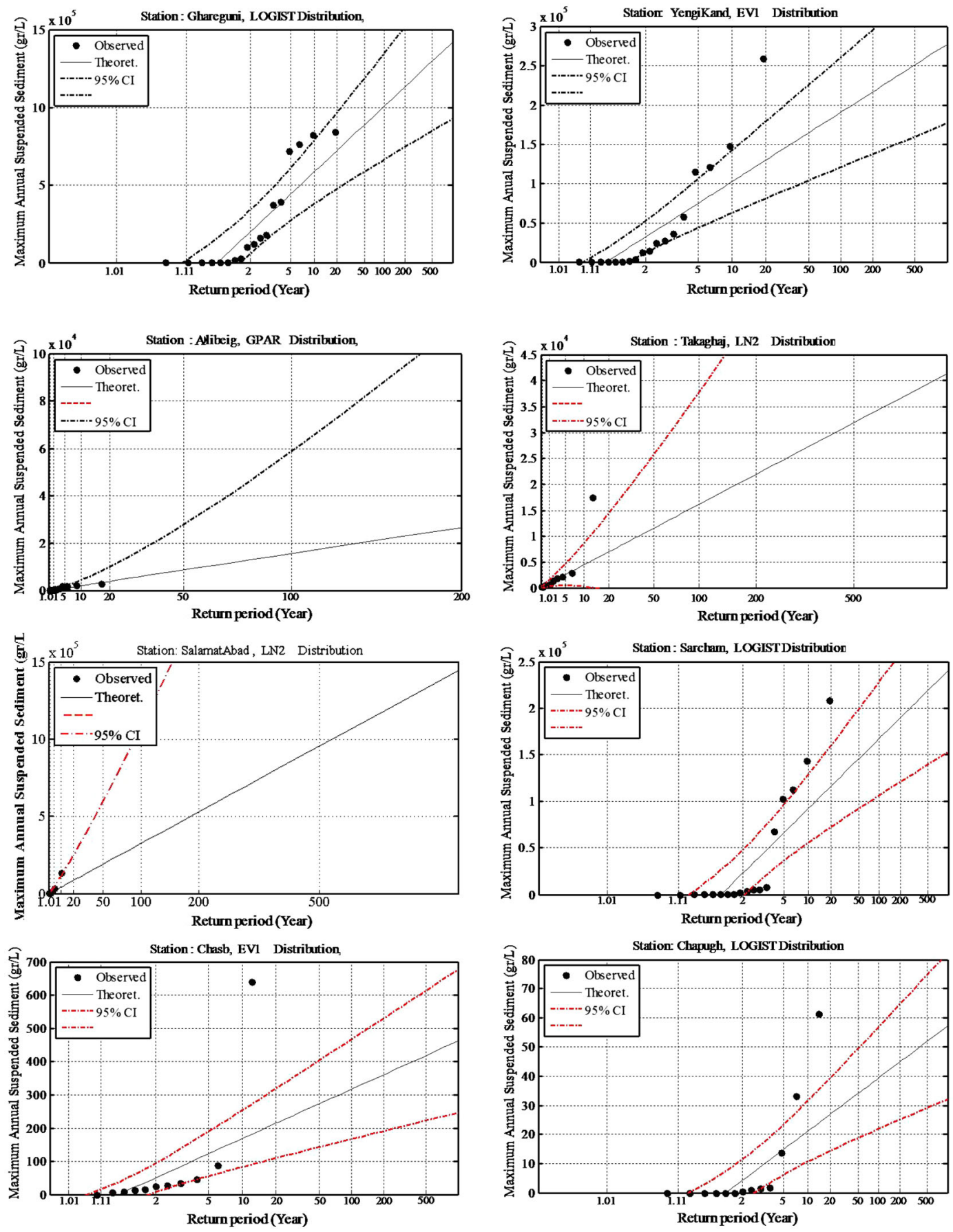

Fig. 4 At site plotting position and quantile estimations for the Annual suspended sediment concentrations of the selected stations

others. Previous studies (Tramblay et al. 2008; Benkhaled et al. 2014) also indicated the better performances of 2-parameter distributions to fit annual SSC data time series. After the selection of the best fit distributions by Goodness-of-fit tests, frequency analysis of SSC and quantile estimation was done by the selected distributions. Results showed that Ghareguni and YengiKand stations with the Logistic and EV1 distributions showed maximum suspended concentrations in all return periods. Other stations including Chasb, Takaghaj and Alibeig stations showed the lower SSC quantities. The maximum rates of SSC in all over the region were observed at 10 years return period with the probability occurrence of $10 \%$ in each year. The results of this study emphasized on the extending biological and structural soil conservation project in the region especially for upstream watersheds of Ghareguni 
Table 4 At-site quantile estimations of stations in the study region

\begin{tabular}{|c|c|c|c|c|c|}
\hline Station & $\mathrm{T}$ & $\mathrm{P}$ & Quantile estimation (gr/L) & Observation $(\mathrm{g} / \mathrm{L})$ & SE \\
\hline \multirow[t]{7}{*}{ Ghareguni } & 2 & 50 & $200,232.26$ & $111,711.81$ & $71,970.03$ \\
\hline & 5 & 20 & $444,621.90$ & $725,454.18$ & 86603.40 \\
\hline & 10 & 10 & $587,580.68$ & $833,095.26$ & $104,923.47$ \\
\hline & 20 & 5 & 719,307 & & $125,091.20$ \\
\hline & 50 & 2 & $886,320.72$ & & $153,192.08$ \\
\hline & 100 & 1 & $1,010,305.30$ & & $175,142.29$ \\
\hline & 200 & 0.5 & $1,133,388.23$ & & $197,511.75$ \\
\hline \multirow[t]{7}{*}{ Yengikand } & 2 & 50 & 31,215 & $32,308.23$ & $10,364.79$ \\
\hline & 5 & 20 & $74,755.33$ & $116,240.69$ & $15,906.76$ \\
\hline & 10 & 10 & 102,859 & $158,412.37$ & $20,405.48$ \\
\hline & 20 & 5 & $129,816.72$ & & $24,964.18$ \\
\hline & 50 & 2 & $164,710.72$ & & $31,045.37$ \\
\hline & 100 & 1 & $190,858.86$ & & $35,678.51$ \\
\hline & 200 & 0.5 & $216,911.60$ & & $40,334.82$ \\
\hline \multirow[t]{7}{*}{ Alibeig } & 2 & 50 & 274.94 & 334.61 & 115.47 \\
\hline & 5 & 20 & 1001.51 & 1898.27 & 451.99 \\
\hline & 10 & 10 & 2051.22 & 2318.93 & 1216.35 \\
\hline & 20 & 5 & 3908.81 & & 3126.24 \\
\hline & 50 & 2 & 8720.63 & & 9850.87 \\
\hline & 100 & 1 & $15,711.08$ & & $22,063.36$ \\
\hline & 200 & 0.5 & $28,081.47$ & & $47,526.47$ \\
\hline \multirow[t]{7}{*}{ Takaghaj } & 2 & 50 & 922.15 & 613.45 & 327.68 \\
\hline & 5 & 20 & 2598.54 & 2468.17 & 1074.52 \\
\hline & 10 & 10 & 4465.94 & $13,103.37$ & 2141.60 \\
\hline & 20 & 5 & 6984.44 & & 3806.89 \\
\hline & 50 & 2 & $11,553.79$ & & 7339.02 \\
\hline & 100 & 1 & $16,108.48$ & & $11,054.85$ \\
\hline & 200 & 0.5 & $21,969.77$ & & $16,221.38$ \\
\hline \multirow[t]{7}{*}{ SalamatAbad } & 2 & 50 & 3434.77 & 3362.15 & 2124.17 \\
\hline & 5 & 20 & $17,811.93$ & $29,158.81$ & $12,818.54$ \\
\hline & 10 & 10 & $42,107.25$ & $121,838.70$ & $35,141.96$ \\
\hline & 20 & 5 & $85,687.99$ & & $81,283.36$ \\
\hline & 50 & 2 & $190,636.79$ & & $207,876.25$ \\
\hline & 100 & 1 & $324,887.51$ & & $386,789.31$ \\
\hline & 200 & 0.5 & $529,206.20$ & & $68,003.52$ \\
\hline \multirow[t]{7}{*}{ Sarcham } & 2 & 50 & 23,610 & 2945.78 & $12,815.47$ \\
\hline & 5 & 20 & $67,127.69$ & $104,411.95$ & $15,421.19$ \\
\hline & 10 & 10 & $92,583.90$ & 149762.06 & $18,683.39$ \\
\hline & 20 & 5 & $116,039.99$ & & $22,274.59$ \\
\hline & 50 & 2 & $145,779.59$ & & $27,278.43$ \\
\hline & 100 & 1 & $167,857.13$ & & $31,187.03$ \\
\hline & 200 & 0.5 & $189,774.11$ & & $35,170.29$ \\
\hline \multirow[t]{7}{*}{ Chasb } & 2 & 50 & 51 & 24.64 & 22.18 \\
\hline & 5 & 20 & 122 & 70.32 & 34.04 \\
\hline & 10 & 10 & 169.02 & 527.13 & 43.66 \\
\hline & 20 & 5 & 214.11 & & 53.42 \\
\hline & 50 & 2 & 272.48 & & 66.43 \\
\hline & 100 & 1 & 316.22 & & 76.35 \\
\hline & 200 & 0.5 & 395.80 & & 86.31 \\
\hline
\end{tabular}


Table 4 continued

\begin{tabular}{lrrccr}
\hline Station & $\mathrm{T}$ & $\mathrm{P}$ & Quantile estimation $(\mathrm{gr} / \mathrm{L})$ & Observation $(\mathrm{g} / \mathrm{L})$ & $\mathrm{SE}$ \\
\hline Chapugh & 2 & 50 & 4.37 & 0.4 & 3.67 \\
& 5 & 20 & 14.97 & 17.62 & 4.42 \\
& 10 & 10 & 21.17 & 50.01 & 5.36 \\
& 20 & 5 & 26.89 & & 6.39 \\
& 50 & 2 & 34.13 & & 7.82 \\
& 100 & 1 & 39.51 & & 8.94 \\
& 200 & 0.5 & 44.85 & & 10.08 \\
\hline
\end{tabular}

and YengiKans stations. Nevertheless the results of this study showed better performances for 2-parameter distributions rather than 3-parameter distributions, however it is recommended to conduct SSC frequency analysis for other regions with different climate and land use schemes.

\section{References}

Achite M, Ouillon S (2007) Suspended sediment transport in a semiarid watershed Wadi Abd Algeria. J Hydrol 343:187-202

Aulenbach BT (2013) Improving regression-model-based streamwater constituent load estimates derived from serially correlated data. J Hydrol 503:55-66

Benkhaled A, Remini B (2003) Analyse de la relation de puissance: débit solide-debit liquide à l'échelle du bassin versant de l'Oued Wahrane (Algérie). Rev Sci Eau 16:333-356

Benkhaled A, Higgins H, Chebana F, Necir A (2014) Frequency analysis of annual maximum suspended sediment concentrations in Abiod wadi, Biskra (Algeria). Hydrol Process 28(12):3841-3854

Burn DH (1994) Hydrologic effects of climatic change in West Central Canada. J Hydrol 160:53-70

Chebana F, Ouarda TBMJ (2011) Multivariate quantiles in hydrological frequency analysis. Environmetrics 22:63-78

Chen YD, Huang G, Shao Q, Xu CY (2006) Regional analysis of low flow using L-moments for Dongjiang basin. South China. Hydrol Sci. J. 51(6):1051-1064

Demmak A (1984) Recherche d'une relation empirique entre apports solides spécifiques et paramètres physico-climatiques des bassins: application au cas algérien. In: Challenges in African Hydrology and Water Resources (Proc. Harare Symp., July 1984), vol 144, IAHS Publications, p 403-414

Dodangeh E, Shao Y, Daghestani M (2012) L-Moments and fuzzy cluster analysis of dust storm frequencies in Iran. Aeolian Res 5:91-99

Dodangeh E, Soltani S, Sarhadi A, Shiau JT (2014) Application of L-moments and Bayesian inference for low-flow regionalization in Sefidroud basin, Iran. Hydrol Process 28:1663-1676

El Adlouni S, Bobée B, Ouarda TBMJ (2008) On the tails of extreme event distributions in hydrology. J Hydrol 355(1-4):16-33

Eslamian SS, Feizi H (2007) Maximum monthly rainfall analysis using L-moments for an arid region in Isfahan Province, Iran. J Appl Meteorol Climatol 46(4):494-503

Farsadnia F, Rostami Kamrood M, Moghaddam Nia A, Modarres R, Bray MT, Han D, Sadatinejad J (2014) Identification of homogeneous regions for regionalization of watersheds by two-level self-organizing feature maps. J Hydrol 509(387):1-22
Greenwood JA, Landwehr JM, Matalas NC, Wallis JR (1979) Probability weighted moments: definition and relation to parameters of several distributions expressible in inverse form. Water Resour Res 15(5):1049-1054

Hailegeorgis TT, Thorolfsson ST, Alfredsen K (2013) Regional frequency analysis of extreme precipitation with consideration of uncertainties to update IDF curves for the city of Trondheim. J Hydrol 498:305-318

Hebal A, Remini B (2011) Choix du modèle fréquentiel le plus adéquat à l'estimation des valeurs extrêmes de crues (cas du Nord de L'Algérie). Revue canadienne de génie Civil 38:881-892

Jaiswal RK, Goel NK, Singh P, Thomas T (2002) L-Moment base flood frequency modelling. J Inst Eng (India) 84:6-10

Knighton D (1998) Fluvial forms and processes: a new perspective. Arnold Publishers, London 383 p

Kroll CK, Vogel RM (2002) Probability distribution of low streamflow series in the United States. J Hydrol Eng 7(2):137-146

Kumar R, Chatterjee C, Kumar S, Lohani AK, Singh RD (2003) Development of regional flood frequency relationships using L-moments for Middle Ganga Plains Subzone 1(f) of India. Water Resour Manage 17(4):243-257

Lim YH, Lye LM (2003) Regional flood estimation for ungauged basins in Sarawak, Malaysia. Hydrol Sci J 48(1):79-94

Meddi M (1992) Hydro-pluviométrie et transport solide dans le bassin versant de l'oued Mina (Algérie). Thèse de doctorat, Université Louis Pasteur, Strasbourg, p 285

Modarres R (2008a) Regional frequency distribution type of low flow in North of Iran by L-moments. Water Resour Manag 22(7):823-841

Modarres R (2008b) Regional maximum wind speed frequency analysis for the arid and semi arid regions of Iran. J Arid Environ 72(7):1329-1342

Modarres R, Sarhadi A (2011) Statistically-based regionalization of rainfall climates of Iran. Global Planet Change 75(1):67-75

Montanher OC, Novo EMLM, Barbosa CFC, Renno CD, Silva TSF (2014) Empirical models for estimating the suspended sediment concentration in Amazonian white water rivers using Landsat 5/TM. Int J Appl Earth Obs 29:67-77

Neslihan S (2009) Regional Flood Frequency Analysis Using Index Flood Method Based on L-Moments. PhD. Dissertation, University of Cukurova. Ankara, Turkey

Othman F, Sadeghian MS, Ebrahimi F, Heydari M (2013) A Study on Sedimentation in Sefidroud Dam by Using Depth Evaluation and Comparing the Results with USBR and FAO Methods. In: 2nd International Conference on Environment, Energy and Biotechnology. doi:10.7763/IPCBEE.V51.9, p 43-48

Ouarda TBMJ, Ashkar F, Bensaid E, Hourani I (1994) Statistical distributions used in hydrology. Transformations and asymptotic properties, Scientific Report, Department of Mathematics, University of Moncton, p 31 
Pasquini AI, Lecomte KL, Piovano EL, Depetris PJ (2006) Recent rainfall and runoff variability in central Argentina. Quat Int 158:127-139

Pearson CP (1995) Regional frequency analysis of low flows in New Zealand rivers. J Hydrol NZ 33:94-122

Probst JL, Amiotte Suchet P (1992) Fluvial suspended sediment transport and mechanical erosion in the Maghreb (North Africa) Hydrol. Sci J 37(6):621-637

Rao AR, Hamed KH (2001) Flood frequency analysis. CRC Press, New York, p 355

Rodrigo FS, Esteban-Parra MJ, Pozo-Vázquez D, Castro-Diez Y (1999) A 500-year precipitation record in southern Spain. Int J Climatol 19:1233-1253

Sarhadi A, Soltani S, Modarres R (2012) Probabilistic flood inundation mapping of ungauged rivers: Linking GIS techniques and frequency analysis. J Hydrol 458-459:68-86

Terfous A, Meghounif A, Bouanani A (2001) Etude du transport solide dans l'oued Mouilah. Rev Sci Eau 14(2):173-185
Tramblay Y, St-Hilaire A, Ouarda TBMJ (2008) Frequency analysis of maximum annual suspended sediment concentrations in North America. Hydrol Sci J 53:236-252. doi:10.1623/hysj.53.1.236

Wang YG, Tian T (2013) Sediment concentration prediction and statistical evaluation for annual load estimation. J Hydrol 482:69-78

White R (2001) Evacuation of sediments from reservoirs. Thomas Telford Services Ltd, London

Yan B, Fang NF, Zhang PC, Shi ZH (2013) Impacts of land use change on watershed streamflow and sediment yield: an assessment using hydrologic modelling and partial least squares regression. J Hydrol 484:26-37

Yurekli K, Modarres R, Ozturk F (2009) Regional daily maximum rainfall estimation for Cekerek Watershed by L-moments. Meteorol Appl 16:435-444 